\title{
Inhibitory effects of the recombinant human serine protease inhibitor Hespintor on the proliferation, migration and invasion of hepatocellular carcinoma cells
}

\author{
XUE-LEI WANG ${ }^{1}$, YUE LI ${ }^{2}$, XIAO-YAN CHENG ${ }^{2}$, QING CHI $^{1}$, \\ XIAO-KUN YAO ${ }^{1}$, HUI-JUAN WU ${ }^{2}$ and YONG-ZHI LUN ${ }^{1}$ \\ ${ }^{1}$ Liaoning Provincial University Key Laboratory of Biophysics, College of Medicine, Dalian University, \\ Dalian, Liaoning 116622; ${ }^{2}$ Beijing Center for Physical and Chemical Analysis, Beijing 100094, P.R. China
}

Received August 25, 2014; Accepted November 26, 2014

DOI: $10.3892 /$ or.2014.3670

\begin{abstract}
Hespintor is a new Kazal-type serine proteinase inhibitor (Serpin) screened from the HepG2 hepatoblastoma cell line using the suppression subtractive hybridization (SSH) technique. Seprin is closely associated with the progression and remission of malignant tumors, and has certain significance in the diagnosis and treatment of tumors. Investigations on the antitumor activity of Serpin are expected to aid in the development of a new method for tumor treatment based on the serine protease inhibitor. Although the Hespintor prokaryotic expression strain and recombinant Hespintor protein (recombinant fusion protein of Hespintor and rHespintor) have already been obtained, the protein extraction efficiency is low due to the low initial amount of extracted protein and large number of purification steps, which affect the study of the protein function. The aim of the present study was to improve the purification method of rHespintor, increase the protein extraction efficiency, and investigate its effects on the proliferation, migration and invasion of the HepG2 hepatoblastoma cell line. The results demonstrated that the application of urea gradient washing of inclusion body of the protein may effectively remove the majority of impure proteins from the targeted protein. After one-step purification, the target protein rHespintor exhibited a high inhibitory effect of Trypsin Hydrolysis, which was exhibited in a dose-dependent manner. Hoechst 33258 staining was used to determine cell apoptosis. After treating HepG2 hepatoblastoma cells with rHespintor, the cell growth was inhibited, the proliferation
\end{abstract}

Correspondence to: Dr Yong-Zhi Lun, Liaoning Provincial University Key Laboratory of Biophysics, College of Medicine, Dalian University, 10 Xuefu Street, Dalian, Liaoning 116622, P.R. China

E-mail: lunyz@163.com

Dr Hui-Juan Wu, Beijing Center for Physical and Chemical Analysis, Beijing 100094, P.R. China

E-mail: sunnywhj@126.com

Key words: recombinant protein, purification, serine proteinase inhibitor, cell proliferation, cell migration, cell invasion ability was reduced, and the number of migrated and invaded cells were significantly decreased. Hoechst 33258 staining and flow cytometry assay results showed clear cell apoptosis. The results reveal showed that rHespintor significantly inhibited proliferation, migration and invasion of the HepG2 hepatoblastoma cell line in vitro, and induced cell apoptosis to a certain extent, indicating that the recombinant protein Hespintor exerts an antitumor effect in vitro, and has the potential and feasibility to become an antitumor drug.

\section{Introduction}

In the processes of tumor growth, angiogenesis and invasion and metastasis, protease plays the role of the final common pathway, and has an important role in the functional or pathological tissue reconstruction process, in addition to the participation of growth factors, tumor-suppressor gene mutation, cell cycle changes, and other upstream mechanisms (1). The abilities of invasion and metastasis of tumor cells are closely associated with the degradation ability of the extracellular matrix (ECM) and basement membrane (BM) of the protease induced by tumor cells. Inhibition of protease activity may affect cancer development and become an effective method for the treatment of tumors. Protease activity can be regulated at various levels, however, the most direct method is to block the protease activity. Highly expressed protease inhibitors or synthetic protease inhibitors can effectively block the activation of the proteases (1-3) and prevent degradation of the ECM. Therefore, protease inhibitors have become the focus of current studies.

Existing studies have shown that the Kazal family members exert mostly inhibitory effects on protease activity, such as the trypsin inhibitor secreted by the pancreas, acrosin inhibitor, and elastase inhibitory factor (4). Members of the Kazal family are involved in the regulation of tumor cell invasion and metastasis. Zou et al (5) isolated a new gene known as Maspin from normal human breast epithelial cells, by using the subtractive hybridization method. Previous results have demonstrated an enhanced expression of Maspin in many malignant tumors, which may lead to positive outcomes, suggesting that the serine protease inhibitor has antitumor effects (6). The transformation suppressor gene RECK (reversion-inducing systeine-rich 
protein with Kazal motif) isolated by Takahashi et al (7) is widely distributed in a variety of normal human tissues. The accumulation and expression of RECK in tumor cells can significantly inhibit the invasion, metastasis and angiogenesis of tumor cells $(7,8)$. Another member of the Kazal family, TATI (tumor-associated trypsin inhibitor), can be synthesized and secreted by tumor cells, and inhibit the activity of a series of matrix metalloproteinases (MMPs) and prevent tumor cell invasion and metastasis, while the expression of TATI is also involved in the inhibition of tumor cells $(9,10)$. Su et al (11) isolated esopageal cancer-related genes (ECRGs) by using the differential displaying PCR method (DD-PCR), and found that ECRG1, -2 and -4 markedly inhibited the proliferation, migration and invasion of tumor cells, and induced tumor cell apoptosis (12-14).

Hespintor is a new member of the Kazal family, and the length of the open reading frame (ORF) of Hespintor is $285 \mathrm{bp}$, the encoded product of which is a serine protease inhibitor composed of 94 amino acid residues. The analysis results showed that Hespintor is divided into three sections: 1-23 amino acid residues in the $\mathrm{N}$-end are a signal peptide, 35-94 amino acids contain a typical Kazal domain, and 24-34 amino acid residues between the $\mathrm{N}$ terminal signal peptide and Kazal structure domain constitute a linking section. In previous studies (25), the Hespintor-Kazal prokaryotic expression system was successfully constructed. Homology analysis showed that Hespintor and other Kazal family members have both similar and unique characteristics in terms of structure. Therefore, conducting studies on the antitumor activity of Hespintor may be useful for understanding the role of Hespintor in the process of tumor invasion and metastasis, and provide a basis for the future development of drugs in the treatment of cancers based on the serine protease inhibitor Hespintor.

\section{Materials and methods}

Plasmids and strains. Recombinant prokaryotic expression vector pET-40b (+)/Hespintor and Escherichia coli Rosetta (DE3) were obtained from the present laboratory. The HepG2 hepatoblastoma cells were obtained from the Beijing Center for Physical and Chemical Analysis (Beijing, China).

Major reagents. The PageRuler Prestained Protein Ladder was purchased from Thermo Fisher Scientific, Inc. (Wyman, MA, USA). The mouse anti-human His-Tag monoclonal antibody (primary antibody) was purchased from Kebaiao Biotech Co., Ltd. (Beijing, China). The goat anti-mouse HRP-IgG (secondary antibody) was purchased from Sequoia Jinqiao Biological Technology Co., Ltd. (Beijing, China). The bovine serum albumin (BSA) and trypsin (activity $\geq 250 \mathrm{NF} \mathrm{U} / \mathrm{mg}$ ) were purchased from Amresco, Inc. (Solon, OH, USA). The Na-benzoyl-DL-arginine-p-nitrophenyl amide hydrochloride (BAPNA) was purchased from Sigma (St. Louis, MO, USA). The $\mathrm{Ni}^{2+}$ column $\left(\mathrm{Ni}^{2+}\right.$-Histrap FF crude $\left.5 \mathrm{ml}\right)$ was purchased from GE Healthcare Co. (Piscataway, NJ, USA). The BCA protein assay kit was purchased from Seitz Biological Co., Ltd. (Beijing, China).

Extraction of the recombinant protein Hespintorfrom the inclusion body. The positive clone of the Rosetta (DE3)/Hespintor/
pET-40b (+) single colony was screened and inoculated in an LB liquid medium with kanamycin and chloramphenicol for $8 \mathrm{~h}$ at $37^{\circ} \mathrm{C}$. Amplification culture was conducted on the cells according to the proportion, when the concentration of the cells was OD600 $=0.6-0.8$, the final adding concentration of IPTG was $0.25 \mathrm{mmol} / 1$ at $30^{\circ} \mathrm{C}$, and the cells were induced for $5 \mathrm{~h}$ at $180 \mathrm{rpm}$.

The induced Rosetta (DE3) bacteria liquid was collected, and the bacteria were harvested. After cell crushing and washing, the recombinant protein precipitation of the inclusion body was resuspended in an $8 \mathrm{M}$ urea lysis buffer (binding buffer). The obtained supernatant was filtered through a $0.45 \mu \mathrm{m}$ membrane for subsequent use.

Purification and renaturation of the inclusion body of recombinant protein Hespintor. The purification of the inclusion body solution was conducted according to the purification operation of the $6 \mathrm{X}$ His histidine-tagged protein affinity chromatography. The binding buffer was used to balance the Ni column. After balancing, low-speed centrifugation was conducted on the $10 \mathrm{ml}$ loading pre-column protein solution after dilution. The entire process was performed at $4^{\circ} \mathrm{C}$. After loading the sample, the binding buffer was used continuously to wash flat baseline, then 20 repetitions of the refolding buffer were used for the renaturation of the column protein. The elution buffer was then used to collect the 280-nm absorption peak of the targeted protein. After conducting electrophoresis analysis of 12\% SDS-PAGE, the collected protein was added to the dialysis bag for further purification with PBS as the buffer. Following completion of dialysis, the protein was collected again and the protein concentration was measured and stored at $-20^{\circ} \mathrm{C}$ for subsequent use.

Activity identification of the recombinant protein Hespintor. The BCA protein assay kit was used to measure the protein concentration of the obtained and purified rHespintor. According to previous reports and the optimized method, the enzyme activity of rHespintor was measured $(15,16)$. The $0.1 \mathrm{M}$ Tris buffer ( $\mathrm{pH} 8.0$ ) containing $0.4 \% \mathrm{CaCl}_{2}$ was used to regulate the concentration of the Hespintor up to $0.2 \mathrm{mg} / \mathrm{ml}$. An amount of the Hespintor was taken to react with $100 \mu \mathrm{l}$ $0.1 \mathrm{mg} / \mathrm{ml}$ trypsin (Trypsin, Sigma), with the mass ratios between the rHespintor and trypsin in the reaction system adjusted to $1: 4,1: 2,1: 1,2: 1,3: 1,4: 1$ and 5:1, respectively. A $300 \mu \mathrm{l}$ reaction substrate BAPNA $(1 \mathrm{mg} / \mathrm{ml})$ was then added to the mixture for incubation at $37^{\circ} \mathrm{C}$ in a water bath for $10 \mathrm{~min}$. Acetic acid (30\%) was added to the mixture for full mixing to terminate the reaction. Prior to detection, centrifugation at $8000 \mathrm{x} \mathrm{g}$ was conducted at room temperature for $3 \mathrm{~min}$ on the mixture to remove the effects of the undissolved BAPNA on detection. A spectrophotometer was used to determine the A410 nm value of the sample without adding rHespintor as the negative control group. Based on this method, the dose inhibitory effect of the rHespintor on the hydrolysis of trypsin was analyzed.

The inhibition rate of the recombinant protein Hespintor was calculated according to the following formula to draw the inhibition curve:

$$
\text { Inhibition } \%=\frac{\left(\Delta A_{410 \mathrm{~nm}} \text { Unhibited }-\Delta A_{410 \mathrm{~nm}} \text { Inhibition }\right)}{\left(\Delta A_{410 \mathrm{~nm}} \text { Unhibited }-\Delta A_{410 \mathrm{~nm}} \text { Blank }\right)} \times 100 \%
$$


Inhibition assay of cell proliferation. The HepG2 cells in the logarithmic growth phase were obtained for vaccination on a 96-well plate with $200 \mu \mathrm{l}$ in each well in $5 \% \mathrm{CO}_{2}$ at $37^{\circ} \mathrm{C}$ for overnight culturing. The following day, different concentrations of the recombinant protein Hespintor were used to treat the cells at the final concentration of Hespintor as 1, 2, 4, 8, 12 and $16 \mu \mathrm{g} / \mathrm{ml}$. In addition, a drug-free negative control group, blank group and cisplatin (DDP)-positive control group were established at the same time. Each group had five repeated holes. After culturing for 48 and $72 \mathrm{~h}, 20 \mu \mathrm{l}, 5 \mathrm{mg} /$ ml MTT was continuously added for culturing for $4 \mathrm{~h}$. After discarding the supernatant, $150 \mu \mathrm{l}$ DMSO was added to each hole, followed by gentle agitation for $10 \mathrm{~min}$. A570 $\mathrm{nm}$ of the cells was detected by a microplate reader. The survival rate of the tumor cells was calculated according to the formula:

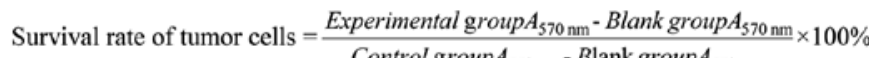
Control group $A_{570 \mathrm{~nm}}-{\text { Blank group } A_{570 \mathrm{~nm}}}$

Cell-wound healing assay. When the HepG2 cells in a 6-well plate were cultured in vitro to the $90 \%$ fusion state, a $10 \mu \mathrm{l}$ pipette tip was used to draw the line along the bottom section. The cells were washed three times with PBS, then DMEM $(10 \%$ FBS) containing rHespintor with concentrations of 0,10 and $20 \mu \mathrm{g} / \mathrm{ml}$ were added. Subsequent to culturing at $37^{\circ} \mathrm{C}$ in $5 \%$ $\mathrm{CO}_{2}$ for 0,12 and $24 \mathrm{~h}$, and images of the cells were captured.

Invasion assay of tumor cells. The matrigel in the BM was diluted with the precooling serum-free DMEM. The prepared matrigel was subsequently used to coat the upper chamber of the Transwell 24-hole plate $(8 \mu \mathrm{m}$, Corning Inc., Corning, NY, USa). The HepG2 cells were treated with the rHespintor at final concentrations of 0,5 and $10 \mu \mathrm{g} / \mathrm{ml}$ for 4 days $(17,18)$. The medium was then discarded. The cells were cultured with the serum-free medium for $12 \mathrm{~h}$, the cells were digested with $0.25 \%$ trypsin and adjusted to the cell density to $4 \times 10^{5} / \mathrm{ml}$. Then, $200 \mu \mathrm{l}$ cell suspension was added to the upper chamber and $500 \mu \mathrm{l}$ DMEM including $0.1 \% \mathrm{FBS}$, $40 \mathrm{ng} / \mathrm{ml} \mathrm{rHGF}$ and containing $\mathrm{rHGF}$ as a chemotactic factor was added to the lower chamber (19). The cells were cultured in $5 \% \mathrm{CO}_{2}$ at $37^{\circ} \mathrm{C}$ for $24 \mathrm{~h}$. The cells were removed from the chamber and fixed with pre-cooling formalin for $20 \mathrm{~min}$, and washed twice with PBS. The washed cells were stained with crystal violet in the dark for $30 \mathrm{~min}$, and again washed twice with PBS. Cotton buds were used to gently scrape the cells on the upper chamber surface of the polycarbonate membranes. The diaphragm was carefully cut off and placed on a glass slide, to which neutral quick drying glue was added, and the cover glass was used to seal it. Cells were counted under a microscope in five random fields per membrane, and each experiment was repeated three times.

Tumor cell migration experiment. The basic steps were identical to those of the invasion assay, with the exception that no coated gel was used.

Detection of cell cycle and apoptosis. The HepG2 cells were treated with rHespintor with the final concentrations of 0,5 and $10 \mu \mathrm{g} / \mathrm{ml}$ for 4 days. The culture medium was collected in the centrifuge tube for further use. Trypsin $(0.25 \%)$ was used to digest the adherent cells. The previously collected culture solution was added to the cells to gently collect the cells. The collected cells were the harvested in an EP tube for centrifugation at $1200 \mathrm{x} \mathrm{g}$ for $3 \mathrm{~min}$. The supernatant was discarded carefully. The cells were suspended in PBS and washed twice. Pre-cooled $70 \%$ ethanol was used to decentralize and fix the cells for $2 \mathrm{~h}$. After centrifugation at $1200 \mathrm{x} \mathrm{g}$ for $3 \mathrm{~min}$, the supernatant was carefully discarded. The pre-cooled PBS was used to suspend the cells for another round of washing. A propidium iodide staining solution was then added to gradually and fully suspend the cells in a $37^{\circ} \mathrm{C}$ water bath for $30 \mathrm{~min}$ in the dark. Following filtration, flow cytometry was used in the measurement and analysis of the experimental results.

Cell apoptosis and Hoechst 33258 staining. The sterilized coverslip was immersed in $75 \%$ ethanol for $5 \mathrm{~min}$, and washed three times with an aseptic PBS medium. After washing with the culture medium, the coverslips were placed in a 6-well plate. The HepG2 cells in the logarithmic growth period were digested with trypsin and adjusted to the cell density of $1 \times 10^{4} / \mathrm{ml}$. Each well was seeded with $1 \mathrm{ml}$ cells for culturing for $24 \mathrm{~h}$ until the cells were adhered onto the cell culture plate surface. The cells were treated with rHespintor at final concentrations of 0,10 and $20 \mu \mathrm{g} / \mathrm{ml}$ for $36 \mathrm{~h}$ to induce cell apoptosis. After induction was complete, the supernatant culture medium was discarded, and $500 \mu 1$ fixative solution was added for $10 \mathrm{~min}$, and saline was used for two rounds of washing. Staining was conducted by adding $500 \mu$ l Hoechst 33258 staining liquid in the dark for $10 \mathrm{~min}$. Physiological saline was used for two rounds of washing with a washing time of 3 min each time. The cover slips were removed carefully, and excess moisture was removed. A quenching agent was dripped on the slide glass for sealing. The morphological changes of the cell nuclei were observed under a fluorescent microscope and images were captured.

\section{Results}

Induction expression of the recombinant protein Hespintor and extraction of the inclusion body. Centrifugation was conducted on the induced Rosetta (DE3) bacteria solution. Bacterial sedimentation was obtained after bacteria were lysed by means of lysyme and centrifugation. SDS-PAGE electrophoresis analysis was performed on the resuspended bacteria precipitate. The recombinant protein Hespintor was identified in the precipitate in the form of inclusion bodies. Urea ( 2 and $4 \mathrm{M}$ ) were used to wash the inclusion body precipitate to remove impurity proteins, and the precipitate was then dissolved in $8 \mathrm{M}$ urea (binding buffer) to obtain the inclusion body dissolving liquid. SDS-PAGE analysis was conducted on the induced entire bacterial pellet and supernatant. The recombinant proteins were shown to be concentrated in the precipitate in the form of inclusion bodies. Two successive rounds of washing with the washing liquid effectively removed the impure proteins and improved the purity of the crude proteins (Fig. 1).

Purification of the recombinant protein Hespintor. The inclusion body dissolving liquid was purified by the $\mathrm{Ni}^{2+}$ affinity 


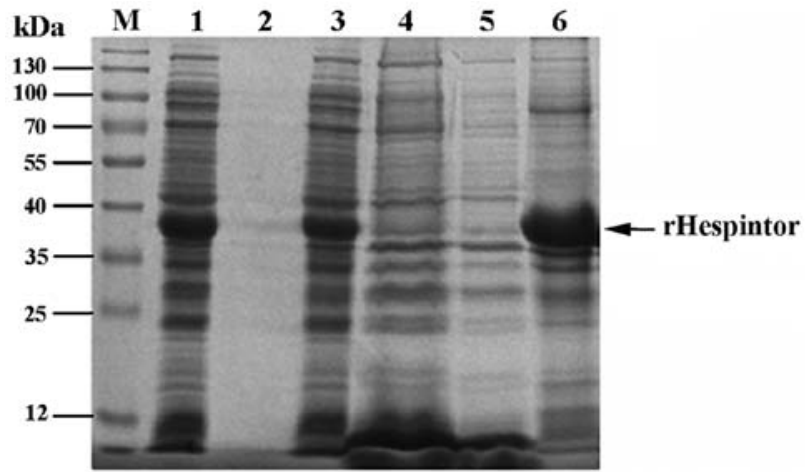

Figure 1. SDS-PAGE analysis of the crude protein extracted from the induced expression stains. M, PageRuler prestained protein ladder; lane 1, induced Rosetta(DE3)/Hespintor/pET-40b(+) supernatant; 2, induced Rosetta(DE3)/ Hespintor/pET-40b(+) precipitate; 3, lysed Rosetta(DE3)/Hespintor/pET$40 \mathrm{~b}(+)$ supernatant; 4 , supernatant for wash once; 5 , supernatant for wash twice; 6 , inclusion body of rHespintor.

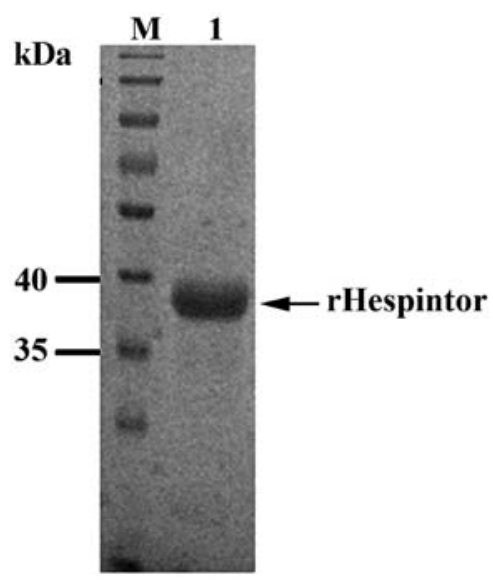

Figure 2. SDS-PAGE analysis of the purified rHespintor.

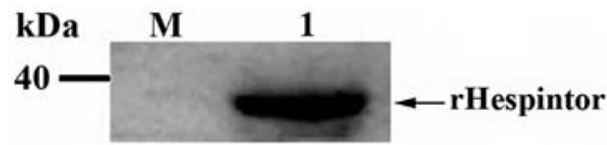

Figure 3. Western blot analysis of the expressed product and the recombinant protein. M, PageRuler prestained protein ladder; lane 1, purified rHespintor.

column, while the refolding process of the recombinant protein Hespintor was completed on the nickel column. After elution, SDS-PAGE analysis was carried out on the obtained protein after desalination by the semipermeable membrane, and a single band was obtained (Fig. 2). The western blotting identification demonstrated that the His.Tag rHespintor was successfully expressed (Fig. 3).

Activity detection of the purified recombinant protein Hespintor. Trypsin is capable of hydrolyzing low molecular weight substrate BAPNA, which can release yellow p-nitroaniline. Yellow p-nitroaniline has a maximum absorbance at $405 \mathrm{~nm}$. If the trypsin inhibitor is added to this reaction system, then the hydrolysis activity of the trypsin is inhibited, which can decrease the absorption value of A405 $\mathrm{nm}$. The results

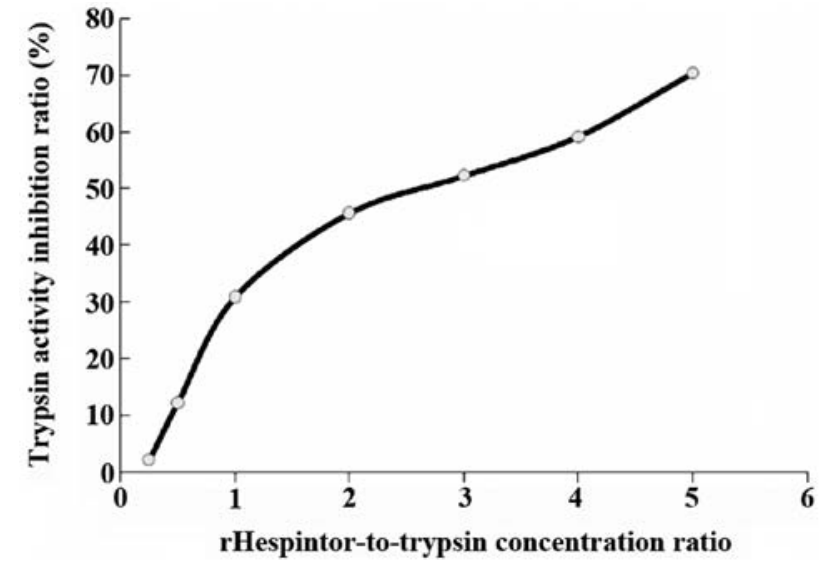

Figure 4. Inhibition of the purified rHespintor on the hydrolysis activity of trypsin.

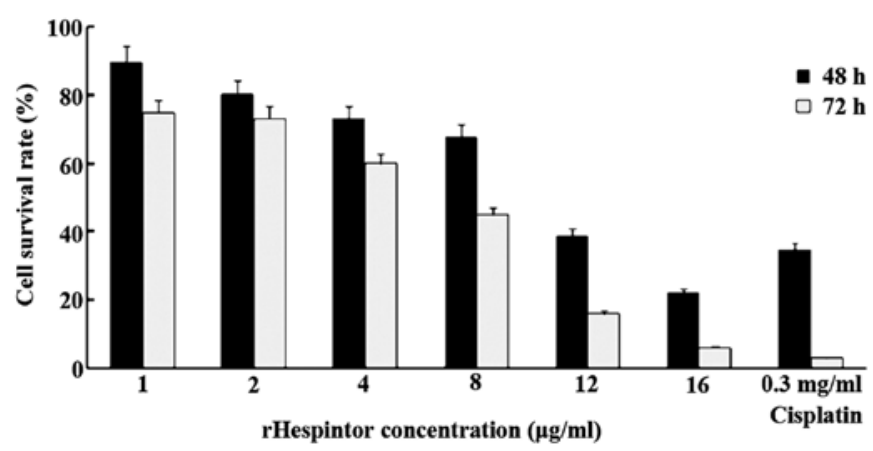

Figure 5. Inhibitory effects of rHespintor on the proliferation of HepG2 cells.

showed that $10 \mu \mathrm{g}$ rHespintor can act on $10 \mu \mathrm{g}$ trypsin, and the rHespintor can inhibit $30.99 \%$ of the activity of trypsin. When the mass ratios between rHespintor and trypsin were 1:4, 1:2, $1: 1,2: 1,3: 1,4: 1$ and 5:1, the respective inhibition rates of the trypsin activity were $2.28,12.37,30.99,45.72,52.29,59.18$ and $70.32 \%$ (Fig. 4).

Effects of the recombinant protein Hespintor on the proliferation of HepG2 cells. The rHespintor has significant inhibitory effects on the growth of HepG2 hepatoma cells. When the treatment times of the rHespintor on the HepG 2 cells were the same, the inhibition roles of the rHespintor were gradually increased with the increase of protein concentrations. When the treatment concentrations of the rHespintor on the HepG2 cells were the same, the inhibition roles of the rHespintor were gradually increased with the increase of the treatment times (Fig. 5).

Effects of the recombinant protein Hespintor on the scratch healing of HepG2 cells. Compared with that of the control group, i.e., the HepG 2 cells, the cell migration ability in the experimental group was significantly higher $(\mathrm{P}<0.05)$. When the treatment times of the rHespintor on the HepG2 cells were the same, the inhibition of cell migration was more evident with the increase of protein concentrations (Fig. 6).

Effects of the recombinant protein Hespintor on the invasion of HepG2 cells. The invasion ability of the HepG2 cells 

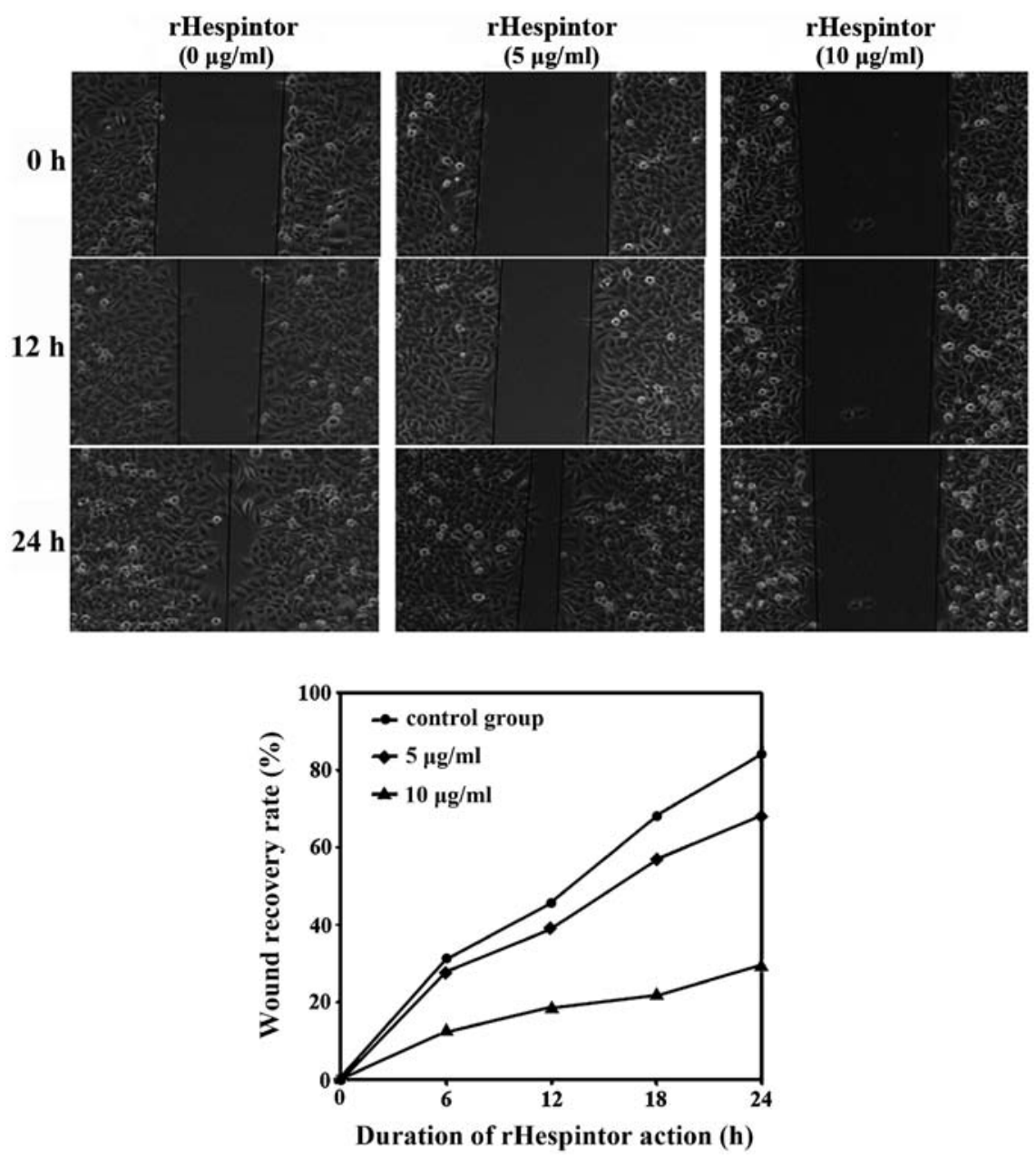

Figure 6. Inhibition effects of rHespintor on the scratch healing ability of HepG2 cells.
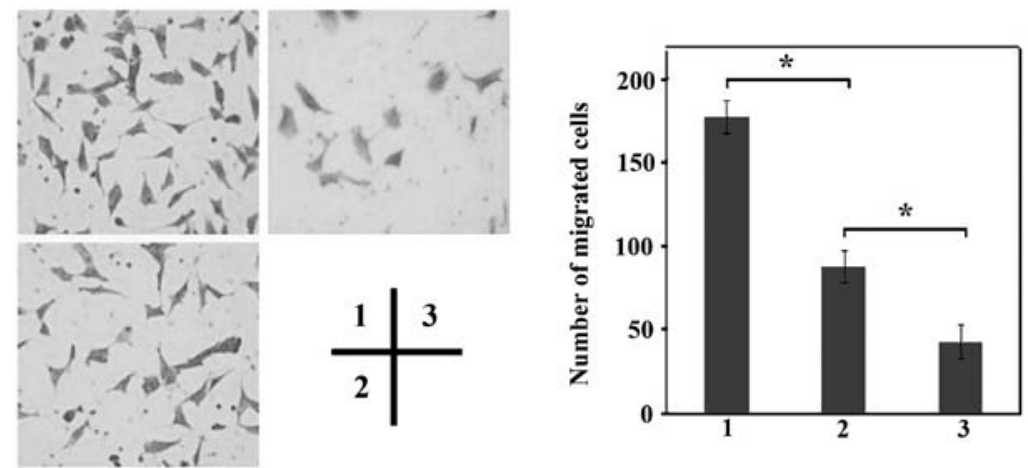

Figure 7. Effects of rHespintor on the invasion ability of HepG2 cells. Panel 1, the control group without rHespintor treatment; panel 2, $5 \mu \mathrm{g} / \mathrm{ml} \mathrm{rHespintor}$ treatment; and panel 3,10 $\mu \mathrm{g} / \mathrm{ml}$ rHespintor treatment. Significant difference between groups was identified ( $(\mathrm{P}<0.05)$

was significantly attenuated after treatment with rHespintor when rHGF was the chemokine $(\mathrm{P}<0.05)$. When the different concentrations of rHespintor were applied to HepG2 cells at the same time, the cell invasion ability was significantly decreased with the increase of protein concentrations (Fig. 7).

Effects of the recombinant protein Hespintor on the cell migration of HepG2 cells. The cell migration ability of the HepG2 cells was significantly attenuated after rHespintor treatment with rHGF as the chemotactic factor, and there were significant differences among the groups $(\mathrm{P}<0.05)$. When the different concentrations of rHespintor were applied to HepG2 cells at the same time, the cell migration ability was significantly decreased along with the increase of rHespintor concentrations (Fig. 8).

Detection results of cell cycle and apoptosis. rHespintor at final concentrations of 0,5 and $10 \mu \mathrm{g} / \mathrm{ml}$ was able to induce cell apoptosis of the HepG2 cells to a certain degree. An increase in rHespintor concentrations resulted in an increase in the cell apoptotic rate. Compared with that of the control 

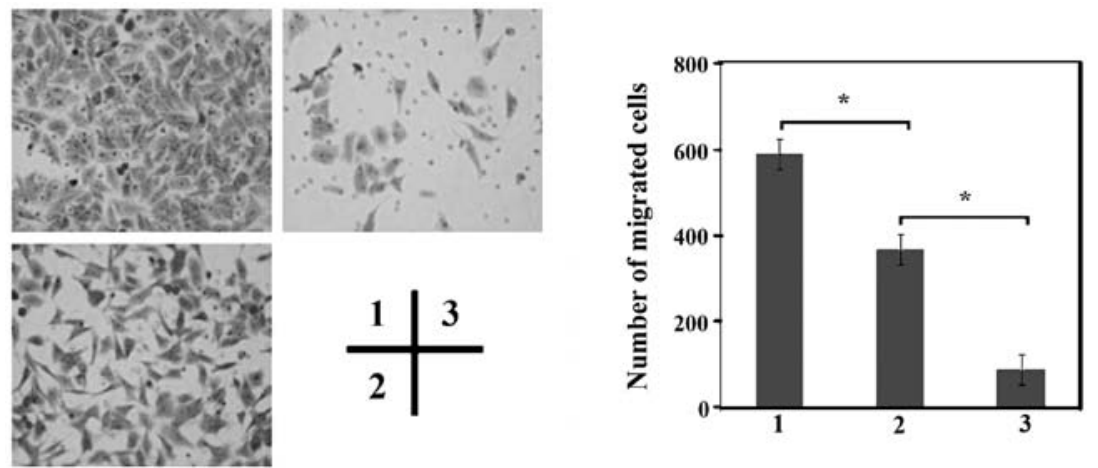

Figure 8. Effects of rHespintor on cell migration of HepG2 cells. Panel 1, the control group without rHespintor treatment; panel 2,5 $\mu \mathrm{g} / \mathrm{ml} \mathrm{rHespintor}$ treatment; and panel $3,10 \mu \mathrm{g} / \mathrm{ml} \mathrm{rHespintor} \mathrm{treatment.}$

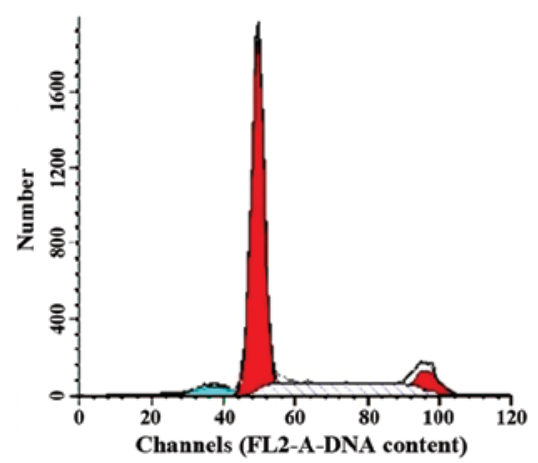

HepG2 0 rHespintor

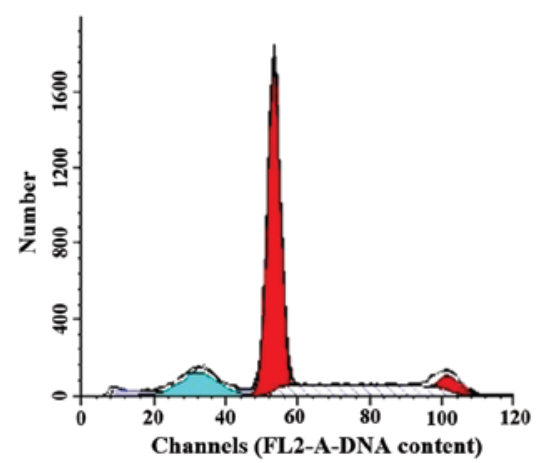

HepG2 $5 \mu \mathrm{g} / \mathrm{ml}$ rHespintor

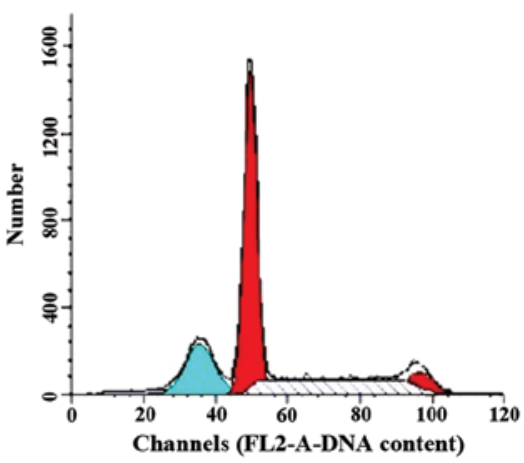

HepG2 $10 \mu \mathrm{g} / \mathrm{ml}$ rHespintor

Figure 9. Analysis of cell cycle and cell apoptotic rate, with blue showing the apoptotic peak.

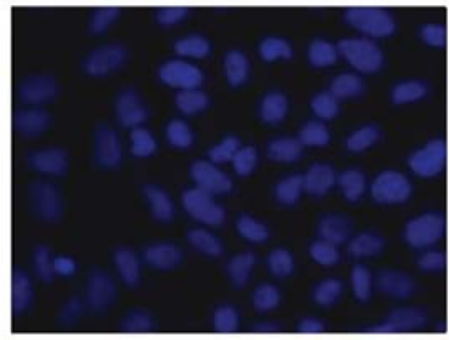

HepG2 0 rHespintor

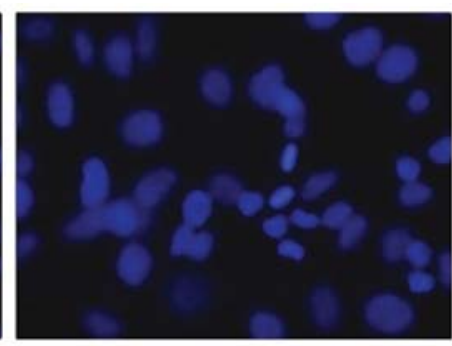

HepG2 $5 \mu \mathrm{g} / \mathrm{ml}$ rHespintor

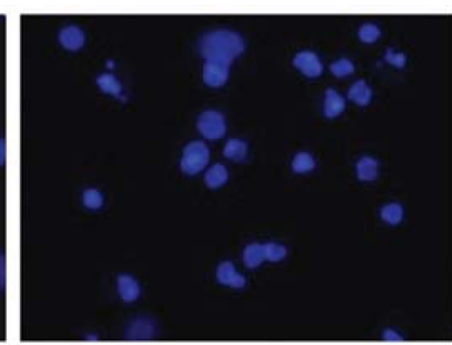

HepG2 $10 \mu \mathrm{g} / \mathrm{ml}$ rHespintor

Figure 10. Morphological changes of HepG2 cells under a fluorescent microscope.

group, significant differences in the cell apoptotic rate were observed $(\mathrm{P}<0.05)$ (Fig. 9).

Cell apoptosis and Hoechst 33258 staining. After staining with fluorescent dye Hoechst 33258, it may be observed in the control group under the microscope that the cell membrane showed integrity, while nucleoplasm staining in the HepG2 cells was uniform. After cell apoptosis chromatin pyknosis was present, and its Hoechst absorbing ability was strong under isotonic conditions, leading to the phenomenon of nuclear dense staining. In the present experiments, the rHespintor with the concentrations of 0,10 and $20 \mu \mathrm{g} / \mathrm{ml}$ were treated with cells for $36 \mathrm{~h}$ to induce cell apoptosis. When the concentration of rHespintor reached $20 \mu \mathrm{g} / \mathrm{ml}$, typical apoptotic morphologies of condensed chromatin and enhanced fluores- cent staining were observed. An increase of the rHespintor concentration resulted in a marked increase in the degree of apoptosis (Fig. 10).

\section{Discussion}

Invasion and metastasis of malignant tumors is the main cause of cancer patient mortality. Tumor invasion and metastasis is a multi-step process, including tumor cell adhesion and de-adhesion, ECM degradation and the reconstruction process, in which the hydrolysis of the ECM of tumor cells is the first step and the molecular basis of tumor invasion and metastasis. Urokinase-type plasminogen activator system can promote the growth of human tumor cells, and is important in the invasion and migration of tumor cells. When uPA combines with uPAR, 
plasmin generation is activated and generated. Plasmin directly degrades the ECM and is involved in the degradation of ECM through the MMP pathway (20-24). Previous results have shown that inhibition of the activity of the UPA/uPAR urokinase-type plasminogen activation system can prevent tumor cell invasion and/or migration $(25,26)$. Since tumor invasion and metastasis cause cancer patient mortality, the identification of safe and effective antitumor drugs with minimal toxic side effects is crucial. A variety of serine protease inhibitors, such as ECRG2, have been shown to suppress the proliferation and invasion of tumor cells and induce tumor cell apoptosis $(27,28)$, and have received relevant attention.

The present study used the previously constructed Hespintor-Kazal prokaryotic expression system (29) and obtained a large quantity of expression of HespintorKazal fusion-tagged proteins using IPTG induction. The Escherichia coli expression system has the characteristics of a clear genetic background, is a simple and rapid process, cost-effective and has a high yield, and a variety of eukaryotic genes have successfully obtained high expressions in E. coli. However, the E. coli expression system cannot conduct posttranslational processing on the eukaryotic proteins after the translation of proteins, and it is difficult to correctly form two disulfide pairings and space conformation, thus the resulting recombinant protein often lacks strong biological activity. When the exogenous gene is expressed in E. coli in high efficiency, it is easy to form inclusion bodies (inclusion body) that gather in the intracellular sections. To obtain a recombinant protein with the same activity as that of the natural protein, the inclusion bodies should first be isolated and washed. A high-concentration denaturant (such as 6-8 M guanidine hydrochloride and 8-10 M urea) is used to dissolve the inclusion bodies, then the inactive and dissolved inclusion body proteins are refolded. The protein is folded correctly and the molecular and natural conformation are recovered.

In the experimental process, the denatured inclusion body proteins are refolded and renatured, which occupies a key step in the process of recombinant protein, and is a difficult issue in biological engineering technology. Each step of the process causes loss of the target protein, as well as a greater number of steps. More steps in the purification of the target protein lead to a greater loss of protein and lower yield rate. In this study, the gradient washing process was enhanced in the protein purification steps to remove the influence of impurities on the purification process of the protein. The basal concentration of imidazole in the buffer was improved to reduce the binding of protein in the host cells to the affinity chromatography column and enhance the binding of histidine tagged proteins. In addition, a Tris buffer solution was used to replace the phosphate-buffered solution to reduce the binding capacity of non-histidine tagged proteins.

In this study, rHespintor was shown to significantly inhibit the proliferation of HepG 2 cells in vitro and inhibit the adhesion and invasion on the matrigel BM. Therefore, rHespintor can inhibit the hydrolysis ability of the ECM and BM in the HepG2 hepatoblastoma cells, thereby inhibiting the metastasis and invasion effects. This process may be achieved through inhibition of the activation of MMPs in the extracellular parts, leading to a decline in ECM degradation ability.

When a tumor is involved in metastasis and invasion, tumor cells destroy the tissue sites to which they adhered, known as the degradation of ECM and BM, and realize invasion, metastasis and angiogenesis. During this process, the tumor cells enhance the release of various proteolytic enzymes. Urokinase-type plasminogen activator (uPA) and its inhibitors (plasminogen activation inhibitor, PAI), as well as MMPs and their inhibitors (tissue inhibits of metalloproteinases, TIMPs) play important roles in the process. Of these, the specific binding of UPA to its receptor UPAR can transform the cell surface plasminogen into plasmin. Plasmin directly degrades fibronectin, laminin, as well as matrix components fibronectin and proteoglycan, and can also activate MMPs for ECM degradation. Therefore, plasminogen activation is the first step of ECM and BM degradation, and the activation of MMPs is important in the degradation of ECM and BM.

This investigation provides a basis for the study of the in vitro development of rHespintor into a new anticancer drug. Future studies are to examine the molecular antitumor mechanism of rHespintor in a more thorough manner and improve its antitumor activity in animals.

\section{Acknowledgements}

This study was supported by the Beijing Engineering Technology Research Centre of Gene Sequencing and Gene Function Analysis.

\section{References}

1. Aureli L, Gioia M, Cerbara I, Monaco S, Fasciglione GF, Marini S, Ascenzi P, Topai A and Coletta M: Structural bases for substrate and inhibitor recognition by matrix metalloproteinases. Curr Med Chem 15: 2192-2222, 2008.

2. Fisher JF and Mobashery S: Mechanism-based profiling of MMPs. Methods Mol Biol 622: 471-487, 2010.

3. Goerge T, Barg A, Schnaeker EM, Poppelmann B, Shpacovitch V, Rattenholl A, Maaser C, Luger TA, Steinhoff M and Schneider SW: Tumor-derived matrix metalloproteinase-1 targets endothelial proteinase-activated receptor 1 promoting endothelial cell activation. Cancer Res 66: 7766-7774, 2006.

4. Empie $M$ and Laskowski $M$ : Thermodynamics and Kinetics of single residue replacements in avian ovomucoid third domains effect on inhibitor interactions with serine proteinases. Biochemistry 21: 2274-2284, 1982.

5. Zou Z, Anisowicz A, Hendrix MJ, Thor A, Neveu M, Sheng S, Rafidi K, Seftor E and Sager R: Maspin, a serpin with tumorsuppressing activity in human mammary epithelial cells. Science 263: 526-529, 1994.

6. Domann FE, Rice JC, Hendrix MJ and Futscher BW: Epigenetic silencing of maspin gene expression in human breast cancers. Int J Cancer 85: 805-810, 2000.

7. Takahashi C, Sheng Z, Horan TP, Kitayama H, Maki M, Hitomi K, Kitaura Y, Takai S, Sasahara RM, Horimoto A, Ikawa Y, Ratzkin BJ, Arakawa T and Noda M: Regulation of matrix metalloproteinase-9 and inhibition of tumor invasion by the membrane-anchored glycoprotein RECK. Proc Natl Acad Sci USA 95: 13221-13226, 1998.

8. Oh J, Takahashi R, Kondo S,Mizoguchi A,AdachiE,SasaharaRM, Nishimura S, Imamura Y, Kitayama H, Alexander DB, Ide C, Horan TP, Arakawa T, Yoshida H, Nishikawa S, Itoh Y, Seiki M, Itohara $\mathrm{S}$, Takahashi $\mathrm{C}$ and Noda $\mathrm{M}$ : The membrane-anchored MMP inhibitor RECK is a key regulator of extracellular matrix integrity and angiogenesis. Cell 107: 789-800, 2001.

9. Span PN, Sweep CG, Manders P, Beex LV, Leppert D and Lindberg RL: Matrix metalloproteinase inhibitor reversioninducing cysteine-rich protein with Kazal motifs: a prognostic marker for good clinical outcome in human breast carcinoma. Cancer 97: 2710-2715, 2003.

10. Masui T, Doi R, Koshiba T, Fujimoto K, Tsuji S, Nakajima S, Koizumi M, Toyoda E, Tulachan S, Ito D, Kami K, Mori T, Wada M, Noda M and Imamura M: RECK expression in pancreatic cancer: its correlation with lower invasiveness and better prognosis. Clin Cancer Res 9: 1779-1784, 2003. 
11. Su T, Liu H and Lu S: Cloning and identification of cDNA fragments related to human esophageal cancer. Zhonghua Zhong Liu Za Zhi 20: 254-257, 1998 (In Chinese).

12. Bachmann K, Shahmiri S, Kaifi J, Schurr P, Mann O, Rawnaq T, Block S, Kalinin V, Izbicki JR and Strate T: Polymorphism Arg290Arg in esophageal-cancer-related gene 1 (ECRG1) is a prognostic factor for survival in esophageal cancer. J Gastrointest Surg 13: 181-187, 2009.

13. Cui Y, Wang J, Zhang X, Lang R, Bi M, Guo L and Lu SH: ECRG2, a novel candidate of tumor suppressor gene in the esophageal carcinoma, interacts directly with metallothionein $2 \mathrm{~A}$ and links to apoptosis. Biochem Biophys Res Commun 302: 904-915, 2003.

14. Yue CM, Deng DJ, Bi MX, Guo LP and Lu SH: Expression of ECRG4, a novel esophageal cancer-related gene, downregulated by $\mathrm{CpG}$ island hypermethylation in human esophageal squamous cell carcinoma. World J Gastroenterol 9: 1174-1178, 2003.

15. Erlanger BF, Kokowsky N and Cohen W: The preparation and properties of two new chromogenic substrates of trypsin. Arch Biochem Biophys 95: 271-278, 1961.

16. Barkia A, Bougatef A, Nasri R, Fetoui E, Balti R and Nasri M: Trypsin from the viscera of Bogue (Boops boops): isolation and characterisation. Fish Physiol Biochem 36: 893-902, 2010.

17. Yang C, Zeisberg M, Lively JC, Nyberg P, Afdhal $\mathrm{N}$ and Kalluri R: Integrin alpha1beta1 and alpha2betal are the key regulators of hepatocarcinoma cell invasion across the fibrotic matrix microenvironment. Cancer Res 63: 8312-8317, 2003.

18. Wu XZ, Chen D and Han XQ: Anti-migration effects of Gekko sulfated glycopeptide on human hepatoma SMMC-7721 cells. Molecules 16: 4958-4970, 2011.

19. Lee WJ, Wu LF, Chen WK, Wang CJ and Tseng TH: Inhibitory effect of luteolin on hepatocyte growth factor/scatter factorinduced HepG2 cell invasion involving both MAPK/ERKs and PI3K-Akt pathways. Chem Biol Interact 160: 123-133, 2006.

20. Ulisse S, Baldini E, Sorrenti S and D'Armiento M: The urokinase plasminogen activator system: a target for anti-cancer therapy. Curr Cancer Drug Targets 9: 32-71, 2009.
21. Gramling MW and Church FC: Plasminogen activator inhibitor-1 is an aggregate response factor with pleiotropic effects on cell signaling in vascular disease and the tumor microenvironment. Thromb Res 125: 377-381, 2010.

22. Schmitt M, Mengele K, Napieralski R, Magdolen V, Reuning U, Gkazepis A, Sweep F, Brünner N, Foekens J and Harbeck N: Clinical utility of level-of-evidence-1 disease forecast cancer biomarkers uPA and its inhibitor PAI-1. Expert Rev Mol Diagn 10: 1051-1067, 2010

23. Schaller J and Gerber SS: The plasmin-antiplasmin system: structural and functional aspects. Cell Mol Life Sci 68: 785-801, 2011.

24. Hildenbrand R, Allgayer H, Marx A and Stroebel P: Modulators of the urokinase-type plasminogen activation system for cancer. Expert Opin Investig Drugs 19: 641-652, 2010.

25. Festuccia C, Dolo V, Guerra F, Violini S, Muzi P, Pavan A and Bologna M: Plasminogen activator system modulates invasive capacity and proliferation in prostatic tumor cells. Clin Exp Metastasis 16: 513-528, 1998.

26. Durko M and Brodt P: Suppression of type I collagenase expression by an-tisense RNA in melanoma cells results in reduced synthesis of the urokinase-type plasminogen activator receptor. Biochem Biophys Res Commun 247: 342-348, 1998

27. Cheng X, Shen Z, Yin L, Lu SH and Cui Y: ECRG2 regulates cell migration/invasion through urokinase-type plasmin activator receptor (uPAR)/beta1 integrin pathway. J Biol Chem 284: 30897-30906, 2009.

28. Song HY, Deng XH, Yuan GY, Hou XF, Zhu ZD, Zhou L and Ren MX: Expression of bcl-2 and p53 in induction of esophageal cancer cell apoptosis by ECRG2 in combination with cisplatin. Asian Pac J Cancer Prev 15: 1397-1401, 2014.

29. Lun YZ, Wang XL and Feng J: Purification and identification of the Kazal domain of a novel serine protease inhibitor, Hespintor, through a bacterial (Escherichia coli) expression system. Int J Mol Med 34: 321-326, 2014. 